CEWP 20-21

\title{
Conditional demand analysis as a tool to evaluate energy policy options on the path to grid decarbonization
}

\author{
Maya Papineau Kareman Yassin Guy Newsham Sarah Brice \\ Carleton University \\ University of \\ Ottawa \\ National Research \\ Council \\ National Research \\ Council
}

December 27, 2020

\section{CARLETON ECONOMICS WORKING PAPERS}
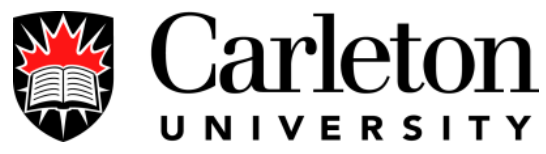

Department of Economics

1125 Colonel By Drive

Ottawa, Ontario, Canada

K1S 5B6 


\title{
Conditional demand analysis as a tool to evaluate energy policy options on the path to grid decarbonization
}

\author{
Maya Papineau* \\ Carleton University \\ Kareman Yassin ${ }^{\dagger}$ \\ UNIVERSITY OF OTTAWA
}

\author{
Guy Newsham ${ }^{\ddagger}$ \\ National Research Council \\ Sarah Brice ${ }^{\S}$ \\ National Research Council
}

December 27, 2020

\begin{abstract}
We implement a conditional demand analysis (CDA) using a large dataset of electricity consumers in a Canadian province with a high market share of electric heating technologies. In doing so we also provide a unifying review of the breadth of interdisciplinary applications of CDA, beginning from the earliest studies up to the present, and test for evidence of unobservable variable bias from random effects panel data estimators. We find that local (i.e. minisplit) heat pumps and thermostat setbacks show the largest electricity savings. Central heat pumps generally do not save heating electricity compared to electric baseboards, and exhibit higher cooling season consumption compared to local heat pumps. We also observe a consistent decline in electricity consumption for newer homes, with the largest effects in the post-2010 period. Our results can inform research to identify promising technologies that support a shift towards large-scale electrification and decarbonization of energy end-uses, on the basis of robust statistical analysis utilizing realized household consumption data.
\end{abstract}

KEYWORDs: Residential electricity consumption; Decarbonization; Energy efficiency; Space-heating; Conditional demand analysis; Climate change; Energy regression models.

*Department of Economics, Carleton University (maya.papineau@carleton.ca), Ottawa, Canada. Corresponding author.

${ }^{\dagger}$ Department of Economics, University of Ottawa (kyass0350uottawa.ca), Ottawa, Canada.

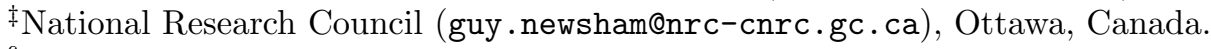

$\S$ National Research Council, Ottawa, Canada. 


\section{Introduction}

Pathways to meeting global decarbonization goals typically include increasing the electrification of end-use services in buildings coupled with lowering the carbon intensity of electricity generation [1, 2]. In buildings, which account for over a third of global emissions [3, 4], the most promising avenues to support a shift to large-scale electrification include reducing heating and cooling emissions through envelope improvements, high-efficiency technology adoption, and increasing usage of renewable energy [5, 2, 6].

To meet the global community's goal to reach net zero carbon emissions by 2050-2070 [7], estimates of future end-use energy consumption loads under higher electrification scenarios are needed. In this context, estimates that disaggregate total energy demand into appliance or equipment-level end-uses have been derived using a number of different methodologies ${ }^{1}$ The statistical methods and engineering models developed in this literature can provide a valuable framework to estimate the impact of technological and behavioural changes in buildings, and support policy-making aimed at increasing both electrification and energy conservation in the coming decades.

This paper implements a conditional demand analysis (CDA) using a large dataset of electricity consumers in a Canadian province with a high market share of electric heating technologies. While originally developed using multiple linear regression techniques in economics [8], CDA has now become widely used in a number of energy-related disciplines. The CDA methodology has also been expanded to include bayesian econometrics and hybrid approaches that incorporate engineering model simulations [16, 10, 17].

Our paper provides three contributions to this existing literature. First, we present a unifying review of the breadth of interdisciplinary applications of CDA, beginning from the earliest studies up to the present. Second, we use econometric techniques that take advantage of a large household-level panel dataset to test for evidence of unobservable variable bias from the random effects model. Unobserved characteristics correlated with both the independent variables of interest and the dependent variable (i.e. consumption at the household level), may result in the consumption level effects of variables of interest being estimated with bias. In that case an alternative estimator, the fixed effects or within estimator, is preferable. However, by construction, the fixed effects estimator implies that only the consumption gradient, which measures how consumption for a particular variable changes as outdoor temperature changes, can be estimated. The advantage of the fixed effects model is that it includes fewer identifying assumptions and therefore the model coefficients can be estimated with more confidence [18]. In addition, the gradient itself may be of interest to policymakers as it can offer insight on the peak load demand of individual variables.

Finally, the particular characteristics of our data setting, a Canadian province with

\footnotetext{
${ }^{1}$ Examples include [8, 9, 10, 11, 12, 13, and [14. [15] provide a comprehensive review of the breadth of methodological approaches that have been utilized to evaluate this question across several disciplines.
} 
a high share of both electrification and low-emission power sources, can help provide insights to researchers and policymakers working on predicting and managing future electrical loads. Canada's electricity grid is among the most decarbonized worldwide: nearly 82 percent of its electricity is derived from non-GHG emitting sources, and in several provinces a significant share of heating demand is met from electricity-using equipment. ${ }^{2}$ In New Brunswick, the province studied in this paper, about 60 percent of electricity is produced using non-emitting sources and almost 52 percent of homes heat their homes using electricity [19, 20]. $:^{3}$

\section{Approaches to estimating appliance energy use}

The primary goal of this study is to estimate robust statistical models to evaluate the effects of energy conservation measures (ECMs) in practice, and inform the development of ECM policies in support of climate policy goals. There are three primary methods used to estimate the energy use of individual appliances and savings from specific ECMs. The first is direct sub-metering of individual devices in multiple houses for a representative period. This will yield very high quality data and energy use estimates. However, this method is also very expensive and invasive; as a result its applications have been limited and these typically utilize small sample sizes, which may limit their generalizability (e.g., [21]; 22]; 23]; 24]).

A second approach is engineering estimates. In this case, the basic power draw of an appliance at the important points in its operational cycle are measured (or estimated), and this is conflated with an assumed usage pattern. The usage pattern may come from a defined standard household definition, or may be estimated by other means [25, 17. This method has relatively low data requirements, but whereas the power measurements may be made unambiguously, the usage patterns may not accurately describe the range of possible patterns in real households.

The third method, and the one used in this paper, is CDA. This is a statistical technique that relies on household appliance ownership data combined with energy use data, collected via survey or directly from utility billing records. More sophisticated models, as in this paper, may be derived with additional survey data on household socio-economic variables and behaviours. It is relatively inexpensive and non-invasive for householders, and was particularly attractive in this research because the necessary data already existed, having been collected by a utility for a different purpose. In the rest of this section we describe the CDA method and evolution of the literature in more detail.

\footnotetext{
${ }^{2}$ There are large variations in the share of non-emitting sources across provinces, from about 12 percent in Alberta to close to 100 percent in Québec.

${ }^{3}$ Another 10 percent use dual electric and wood or dual electric and natural gas systems.
} 


\subsection{The evolution of conditional demand analysis}

\subsubsection{Early work and the basic model}

The CDA model was first introduced in the peer-reviewed literature thirty years ago by Parti and Parti, [8]. Their analysis used linear regression techniques on cross-sectional data to estimate average electricity consumed for 16 appliance types. This early work spurred a number of both peer-reviewed studies and utility-sponsored reports [26, 27, 28, 29, 16, 30, 17, 31, 13.

The specification for estimating appliance-specific consumption in most of these studies is similar to the general formulation

$$
Y_{i t}=\sum_{j=1}^{k} d_{i j} N_{i j} \beta_{j}+\beta_{k+1}+\varepsilon_{i t},
$$

where $Y_{i t}$ and $\varepsilon_{i t}$ are random variables measuring monthly electricity consumption in $\mathrm{kWh}$ and an error term for household $i$ in month $t$, respectively $!^{4}$ The variable $d_{i j}$ is an indicator for ownership of the $j$-th appliance by household $i$, and $N_{i j}$ is the number of appliance $j$ present in household $i$. The coefficients $\beta_{j}$ are interpreted as the estimated consumption of the $j$-th appliance. Finally, $\beta_{k+1}$ is the average consumption of the set of all other unspecified appliances.5

Some studies have extended this model to allow $\beta_{j}$ to vary with socioeconomic, demographic, economic or physical variables such as weather [8, 33, 17]. However, an alternative approach is to directly control for other observable explanatory variables as separate coefficients in the regression or interacted with weather variables [34, 18]. In our empirical specification described below we will estimate different extensions of equation (1) and incorporate the effect of weather on consumption.

Another version of these foundational models utilizes cross-sectional data and assumes that the appliance dummy variables are a function of a random error term to account for variations in the intensity of appliance use, size or capacity among different households. The random error results in a heteroskedastic regression error variance that must be estimated using feasible generalized least squares [35. This is the approach taken by [34] in a study of 380 households in New South Wales, Australia.

Previous literature reviews have synthesized the available estimates from early CDA studies. [36] reviewed 30 separate US CDA studies conducted in the 1980s, and [27] reviewed 15 separate US CDA studies conducted prior to these, with sample sizes typically of several thousand households. It is also noteworthy that the well-established US Residential Energy Consumption Survey (RECS) uses CDA to generate individual end-use

\footnotetext{
${ }^{4}$ Some studies have used a variation of this specification with indoor temperature as a dependent variable 32 .

${ }^{5}$ If time-series data on energy consumption for each household is not available, equation (1) can simply be re-written without the $t$ subscripts.
} 
estimates [37].

In Canada, 38 used data from a comprehensive national energy use survey from 9,773 households to derive estimates of the energy savings associated with upgrading appliances, lighting, and enacting thermostat setbacks. [11] applied CDA to an earlier vintage of the national Canadian dataset used by [38, although electricity and natural gas data were available for only 2,050 and 1,012 households, respectively. 31 used CDA on data from 791 households in British Columbia to develop a model of electricity use. [33] used CDA to study the change in major energy end-uses in Quebec using three large samples of households $(42,000,24,000$, and 46,000) five years apart.

\subsubsection{Hybrid modeling and other innovations}

Researchers also developed hybrid CDA models that incorporate engineering and direct metering approaches. The first example of this approach is [16], who used a Bayesian updating model combining engineering estimates of appliance usage as the prior beliefs and CDA estimates to transform the priors into a posterior distribution of appliance usage. Two other Bayesian analyses, [39] and [10, integrated direct appliance metering data and CDA estimates. [9, 40] also combined metering and CDA analysis using an econometric framework that was shown by [9] to be equivalent to the Bayesian approach. The authors found that this combined approach led to statistical efficiency gains whereby the appliance coefficients could be estimated with more precision even in relatively small samples.

While the existing CDA literature has expanded to include more advanced statistical techniques such as Bayesian updating, hybrid approaches, machine learning and neural network modeling [15], one as yet unstudied but important question is the extent of coefficient bias due to omitted variables [41. We turn to this question in the following section.

\subsection{Panel data estimators for more robust statistical inference}

The now-ubiquitous availability of repeated cross-sections of consumption data from a sample of utility customers, also known as panel data, has enabled researchers to model statistical relationships using an 'error components' framework [42. The error components model allows for research designs whereby individual units differ in unobservable, time-constant ways that affect outcomes of interest. For example, in the short-run when consumer income levels are constant, unobserved customer income in any given sample may be correlated with both appliance use and total energy consumption, resulting in biased coefficient estimates. The same can be said for many other persistent consumer or household-level characteristics such as political ideology or environmental awareness [43].

The error components model is a simple modification of equation (1): 


$$
Y_{i t}=\sum_{j=1}^{k} d_{i j} N_{i j} \beta_{j}+\beta_{k+1}+c_{i}+u_{i t},
$$

where the error $\varepsilon_{i t}=c_{i}+u_{i t}$ now includes both an individual-specific, time-constant component $\left(c_{i}\right)$ and an individual and time-varying term $\left(u_{i t}\right)$. Panel data estimates in the current CDA literature typically adopt the identifying assumptions of the random effects model, in which the $d_{i j}$ and $N_{i j}$ terms are assumed uncorrelated with the composite error term $\varepsilon_{i t}$. This is a strong assumption that is unlikely to be met in most samples that are derived from realized energy consumption and survey data..$^{6}$

An alternative panel model that allows researchers to relax this uncorrelatedness assumption is the fixed effects model. This model allows for correlations between the independent variables of interest and the time-constant error component $c_{i}$, and therefore assume that only $u_{i t}$ is independent of the included right hand side variables. In other words, any time-invariant unobserved variables over the sample period are accounted-for in the fixed effects model. The question of whether the random effects or fixed effects model is most appropriate to obtain unbiased coefficient estimates can be answered using the Hausman [41] and Mundlak tests [44]. We will test this hypothesis in Section 5.1.

One potential drawback of the fixed effects model is that the procedure to eliminate bias from the unobserved $c_{i}$ results in the inability of the statistical model to identify the average effect of an appliance on the level of energy consumption, $Y_{i t}$, as time-invariant variables cannot be identified. However, the consumption gradient, or how consumption changes as temperature changes, can be identified using fixed effects panel estimators. The gradient effects themselves are important from a policy perspective as they indicate potential electricity demand during peak demand periods, and potential peak savings from different conservation measures [45].

\section{Data}

\subsection{Energy and survey data}

The raw data for this analysis came from the 2017 administration of an Energy Planning Survey conducted by NB Power, the primary electric utility in the Canadian province of New Brunswick. Respondents from 6,941 households completed the survey. The survey consisted of more than 80 questions on dwelling and occupant characteristics, household appliances, space conditioning and water heating equipment, fuel usage, and behaviours related to energy consumption. Since we are interested in electricity-using appliances and measures that affect total household energy use, the analysis in this paper focuses only

\footnotetext{
${ }^{6}$ The unobserved income and consumer characteristics from the previous section offer some examples, though there are many other unobserved characteristics this could apply to, including number of occupants or household 'comfort' preferences.
} 
on households reporting their primary heating fuel as being electricity, close to 60 percent of surveyed households. New Brunswick has cold winters and warm but relatively mild summers. In this climate the biggest single energy use is for space heating, and space heating effects will only be apparent in the dependent variable if the space heating is via electric equipment. The primary electric heating equipment in the sample includes both electric baseboards and heat pumps.

Total household electricity use data were obtained from utility records for each billing period spanning approximately one year for most households (12 billing periods). As is common with utility data, the billing periods were approximately one month long but were not typically aligned with the start and end of calendar months, nor were they all the same between households. We divided the energy use in a given billing period by the number of days in that billing period to account for (small) variations in the number of days per billing period between households. The full sample period spans April 1, 2017 to March 31, 2018.

The survey was conducted by the utility for its own planning purposes, and the authors had no role in designing data collection methods. Anonymized data were shared with geographical information denoting the first three digits of the provincial postal code, also known as the "forward sortation area", enough geographical information to facilitate matching with appropriate weather data. Given that over 99 percent of the customers in our sample are served either directly or indirectly from a single utility we assume that all residential customers were exposed to the same prices, and thus price is not a factor in the model. 7

Our final data set after omitting non-electrically heated homes and cleaning the data includes 3,214 households 8 The data summary statistics are presented in Table 1. The annual electricity consumption (in $\mathrm{kWh}$ ) is calculated from utility billing records by aggregating twelve billing periods (April 2017-March 2018) for each household. The remaining variables on house age, size, appliance ownership, energy-related renovations and thermostat setback practices are obtained from the household survey data. Central heat pumps use an internal duct system to distribute conditioned air around the the entire house volume, whereas local heat pumps have an outlet in one or more zones..$^{9}$

The survey asked households whether they turn down their thermostat in the winter while sleeping; when no one is home; both; or never. The thermostat setback variable in Table 1 indicates the share of households reporting any one of the setback practices. Almost three quarters of households report undertaking some form of thermostat setback.

\footnotetext{
${ }^{7}$ Close to 90 percent of the customers in our sample are served directly by NB Power, and two other utilities comprising about nine and one percent of the sample, respectively, purchase their wholesale electricity from the same large utility, resulting in almost identical pricing across the sample.

${ }^{8}$ Appendix A provides further details on our data cleaning approach.

${ }^{9}$ While we have no data on how many zones were served in each house, other studies of similar heat pumps in North America (e.g., [46] Table 6), a large majority service only one zone directly.
} 
Table 1: Summary Statistics

\begin{tabular}{lrrrr}
\hline & Mean & \multicolumn{1}{c}{ S.D. } & \multicolumn{1}{c}{ Min. } & \multicolumn{1}{c}{ Max. } \\
\hline Annual electricity use (kWh) & 18,847 & 7,003 & 3,106 & 41,320 \\
Single detached house & 0.77 & 0.38 & 0 & 1 \\
House size (ft $\left.{ }^{2}\right)$ & 1,521 & 593 & 600 & 2,700 \\
House age (years) & 32.93 & 18.66 & 1 & 62 \\
Number of occupants & 2.23 & 1.03 & 1 & 6 \\
Electric water heater & 0.96 & 0.20 & 0 & 1 \\
Number of dehumidifiers & 0.59 & 0.58 & 0 & 3 \\
Well pump & 0.37 & 0.48 & 0 & 1 \\
Pool pump & 0.07 & 0.26 & 0 & 1 \\
Electric baseboards & 0.49 & 0.50 & 0 & 1 \\
Local heat pump & 0.25 & 0.43 & 0 & 1 \\
Central heat pump & 0.09 & 0.29 & 0 & 1 \\
Number of window AC & 0.26 & 0.58 & 0 & 4 \\
Thermostat setback & 0.74 & 0.44 & 0 & 1 \\
Energy related renovations & 1.08 & 1.54 & 0 & 6 \\
\hline Households & \multicolumn{5}{c}{3,214} \\
\hline
\end{tabular}

Notes: House age was measured by the following seven year built ranges: before 1961, 1961-1974, 1975-1989, 1990-1999, 2000-2009, 2010-2015, and after 2015. The house age variable was calculated by taking the average of each customer's year built range, subtracting that from 2017, and averaging those values. Values above 2015 were recorded as 2016 and values before 1961 recorded as 1955 .

Energy related renovations represents the response to a series of survey questions, "Please indicate if you have recently completed the following: insulate your basement, add insulation to your attic, add insulation to your walls, replace exterior doors or windows, install LED lights, install weather-stripping or caulking." The reported variable is simply the total number of measures the homeowner reported completing. It take on values ranging from 0 to 6 depending on the number of renovations undertaken. On average households in the sample had undertaken about one energy-related renovation.

\subsection{Climate data}

For household energy use related to space heating and cooling, we introduced a dependency on local climate data. The standard indices used in CDA and in building energy studies more generally are heating-degree-days (HDD) and cooling-degree days (CDD), typically to a base temperature of $18^{\circ} \mathrm{C}$, which is considered the typical outdoor temperature at which there is a transition from space heating to space cooling [47]. 10

HDD, which measure demand for space heating services, are calculated by subtracting the average Celsius temperature on a given day from 18 on days with temperatures below

\footnotetext{
${ }^{10}$ Prior studies have used various base temperatures, and there is recognition that there is a wide range of appropriate base temperatures between buildings, depending on their specific construction and operational characteristics. Nevertheless, for large building populations where specific characteristics are not known, $18^{\circ} \mathrm{C}$ persists in being the most common choice for base temperature, and HDD and CDD to this base are the most widely available in published climate data [48.
} 
$18^{\circ} \mathrm{C}$. CDD measure demand for space cooling services and are calculated by subtracting 18 from the average Celsius temperature on a given day with temperatures above $18^{\circ} \mathrm{C},{ }^{11}$ Our data source for these variables was daily weather data from Environment Canada [49]. Further details on our construction of the heating and cooling degree day variables can be found in Appendix A.

\section{Empirical framework}

In this study, monthly energy use and climate data were available, enabling panel regression. With data on a large sample of houses, equation (2) can be solved using either random effects or fixed effects estimators. Regression relies on variability in the explanatory variables. For example, considering data on whether a household has a refrigerator or not, since almost every modern household has a refrigerator of some kind, there is almost no variability in this input. The consequence is that it will be mathematically impossible to separate out refrigerator energy use from other end uses. One way around this, for some variables, is to have additional data, such as total number of refrigerators in the household, which introduces variability through the variable $N_{i j}$ in equations (1) and (2).

Assuming sufficient variability is observed for a given set of variables, the coefficient estimates will depend on the quality of the raw data, and as with most survey-based data sources, householders might not be completely accurate in their responses to the survey questions, or might not interpret the questions in a universal manner. This may introduce noise into the data and if present will reduce the absolute value of any affected coefficients towards zero.

\subsection{Model development}

We followed the process outlined in [11] by first considering logical approaches to modelling individual appliances from engineering principles and the data available. Then we combined these together into a CDA model. Space heating/cooling appliances, energy efficient behaviours of interest to policy makers (thermostat setback, renovations) and household characteristics shown to be influential in prior studies (e.g. house size, number of occupants) were included. Since the fixed effects model does not separately identify time-invariant variables, we interacted most of our variables of interest with climate data (heating and cooling degree days).

We began with a model that included all potential predictors from the survey data, and then began to sequentially remove predictors from the model where predictors offered little variability, or where the predictor did not significantly contribute to the explanatory

\footnotetext{
${ }^{11}$ Temperatures of 18 degrees would be recorded as having zero HDD and CDD, though our temperature data includes decimals and no temperatures of exactly 18 degrees were recorded during our sample period.
} 
power of the model, as measured by $R^{2}$. This process yields the most parsimonious and interpretable model, and is common practice in CDA studies. For example, clothes washers, clothes driers, and electric cookers were dropped as their ownership was almost universal, and was limited to one per house, whereas central air conditioning was dropped because very few households reported ownership (only 35 households).

\subsection{Empirical specifications}

In this section we present our econometric specifications to estimate the electricity consumption effect of specific house characteristics, appliance ownership, space thermal conditioning equipment and behaviours intended to reduce energy use. We also explain the different model identifying assumptions.

\subsubsection{Traditional CDA random-effects specification}

The traditional panel data CDA model consists of estimating equation (1) using the random effects estimator [50, in which the coefficients of interest are estimated without bias if both the strict exogeneity and uncorrelated effects assumptions hold. Strict exogeneity assumes that after conditioning on all the independent variables of interest available to the researcher $\left(d_{i j}\right.$ and/or $\left.N_{i j}\right)$, the error term $\varepsilon_{i t}$ is uncorrelated with these variables as well as any unobserved variables correlated with the variables of interest. Uncorrelated effects assumes that after conditioning on the available variables, any unobserved individual-level and time-constant variables that affect energy consumption (represented by $c_{i}$ ), such as income in the short-run, are uncorrelated with the variables of interest.

With a rich set of explanatory variables to control for, the strict exogeneity assumption will frequently be assumed to be satisfied. However, the uncorrelatedness assumption effectively assumes that any included variables are orthogonal to the composite error term $\varepsilon_{i t}=c_{i}+u_{i t}$, which includes an individual-level, time-constant unobserved variable $c_{i}$ that is likely to be correlated with electricity consumption, as previously noted in Section 2.2. If this is the case, the estimated variables in the random effects model will be biased and a fixed effects estimator, which is identified with less stringent assumptions, should be used instead 12

Since the fixed effects estimator explicitly controls for all time-invariant factors that could affect electricity consumption, the coefficients on variables that do not vary over time cannot be separately identified or estimated. However, an alternative approach that has been taken in prior studies to overcome this constraint is to estimate how variables of interest vary in response to weather changes, by interacting these variables with heatingand cooling degree-days [18, 52. We proceed below using this approach, first by estimating weather-interacted variables using a random effects estimator, followed by estimating

\footnotetext{
${ }^{12}$ This is the approach taken by [51] in the context of evaluating links between economic growth and environmental degradation.
} 
the same model using the fixed effects estimator. With the coefficient estimates for both sets of estimators in hand, we are then able to conduct two different statistical tests to evaluate the evidence for the presence of omitted variable bias in the random effects specification.

We estimate the following random-effects specification:

$$
Y_{i t}=\alpha+\sum_{j=1}^{k} \beta_{1 j} d_{i j} N_{i j} * A H D D_{z t}+\sum_{j=1}^{k} \beta_{2 j} d_{i j} N_{i j} * A C D D_{z t}+\eta_{t}+\varepsilon_{i t}
$$

The outcome variable $Y_{i t}$ in equation (3) is electricity consumption in kWh for household $\mathrm{i}$ in billing period $\mathrm{t}$, and $\alpha$ is the regression constant term. As explained in section 2.1 of the paper, the variable $d_{i j}$ is an indicator for the $\mathrm{j}$-th appliance, behavior or characteristic of household i, while $N_{i j}$ is the number of units of $d_{j}$ present in household i.

Our reported model incorporates a total of seven primary variables of interest. Four indicator variables take the value of 1 if household $i$ owns the following appliances and zero otherwise: pool-pump and three options for households' primary heating systems. The three heating systems are electric baseboard, local heat pump (also known as ductless or minisplit heat pumps), and central air source heat pump. Since their ownership are mutually exclusive, we omit electric baseboard heating systems from the analysis so that the econometric results are interpreted relative to this omitted category. This is the logical choice for results interpretation because heat pumps are often proposed as a more efficient replacement for baseboards. In addition, the model has three independent variables that reflect the number of the following appliances: dehumidifiers, window air-conditioners, energy-related renovations.

The variables $A H D D_{z t}$ and $A C D D_{z t}$ are average daily cooling and heating degree days for a household in billing month $\mathrm{t}$ and located in weather region $\mathrm{z}$. These two variables were obtained by dividing our heating and cooling degree day variables $\left(H D D_{z t}\right.$ and $C D D_{z t}$, respectively) by the number of days in the monthly billing period. We interact our regressors of interest with $A H D D_{z t}$ and $A C D D_{z t}$ to estimate how electricity usage changes in response to a 1 unit change in $A H D D_{z t}$ or $A C D D_{z t}$. $\beta_{1}$ and $\beta_{2}$ when $d_{i j}=1$ and $N_{i j}=1$ are interpreted as the change in monthly usage (demand) of electricity for households who possess a certain appliance relative to those who do not, in response to a one unit increase in $A H D D_{z t}$ and $A C D D_{z t}$, respectively. If $d_{i j}=1$ and $N_{i j}>1$, $\beta_{1}$ and $\beta_{2}$ are interpreted as the additional electricity demand from one extra unit of the appliance in response to a one-unit change in $A H D D_{z t}$ and $A C D D_{z t}$, respectively.

We control for billing period as denoted by $\eta_{t}$, and $\varepsilon_{i t}=c_{i}+u_{i t}$ is the error term that incorporates the household-specific random effects $c_{i}$, which are not explicitly estimated in the random effects model. 


\subsubsection{Fixed-effects model}

We also estimate a fixed-effects model where the uncorrelatedness assumption of the random-effects specification is relaxed. In other words, the fixed-effects estimator accounts for the impact of any time-invariant characteristics that may be correlated with the independent variables.

Statistically, the key distinction between fixed-effects and random-effects specifications is whether we model the correlation between the individual effects, $c_{i}$, and the covariates ( $d_{i j}$ and/or $N_{i j}$ ), or whether we assume that they are independent. In fixed-effects models we explicitly estimate $c_{i}$, a household-specific coefficient that captures the effect of unobserved, time-invariant household characteristics.

Hence, to estimate the effect of energy conservation measures such as appliance ownership, space thermal conditioning equipment and behaviours, which are all time invariant variables, we estimate the fixed-effects specification by interacting these variables with heating and cooling degree days:

$$
Y_{i t}=\alpha+\sum_{j=1}^{k} \beta_{1 j} d_{i j} N_{i j} * A H D D_{z t}+\sum_{j=1}^{k} \beta_{2 j} d_{i j} N_{i j} * A C D D_{z t}+\eta_{t}+c_{i}+u_{i t}
$$

The regressors of interest and interpretation of $\beta_{1}$ and $\beta_{2}$ are similar to the random effect specification defined above in equation (3).

To evaluate whether the fixed-effects or random-effects model is most appropriate in our setting, we use the Mundlack test [44] as well as the Hausman endogeneity test [41]. These results are reported in the following section.

\section{Results}

For our empirical analysis we have a balanced panel data set of 12 billing periods among 3,214 households, for a total of 38,568 observations. In this section we report the results of estimating models using both fixed effects and random effects estimators, then implement the Mundlak and Hausman tests to evaluate whether the random effects specification is likely to be estimated without bias. With these results about model choice in hand, we then move on to discuss specific coefficient estimates in more detail as well as their implications for energy policy in the context of grid decarbonization.

Table 2 presents results from estimating the change in electricity usage that results from home characteristics and energy conservation measures such as appliance ownership, space thermal conditioning equipment and household behaviours in response to cooler/warmer temperature. The two different panel estimators introduced in Section 4.2 are implemented here: column (1) of Table 2 presents results from the estimation of 
Table 2: Random effects and fixed effects model results

\begin{tabular}{|c|c|c|c|c|}
\hline & \multicolumn{2}{|c|}{ Random Effects } & \multicolumn{2}{|c|}{ Fixed Effects } \\
\hline & $(1)$ & $(2)$ & (3) & (4) \\
\hline Independent Variables & Coefficients & Annual Usage & Coefficients & Annual Usage \\
\hline Number of dehumidifiers \# AHDD & $\begin{array}{c}6.584 * * * \\
(1.214)\end{array}$ & 976.04 & $\begin{array}{c}6.123 * * * \\
(0.708)\end{array}$ & 907.70 \\
\hline Poolpump \# ACDD & $\begin{array}{c}378.994 * * * \\
(42.597)\end{array}$ & 1400.38 & $\begin{array}{c}280.019 * * * \\
(32.954)\end{array}$ & 1034.67 \\
\hline Local heat pump \# AHDD & $\begin{array}{c}-16.596^{* * *} \\
(1.516)\end{array}$ & -2460.26 & $\begin{array}{c}-17.599 * * * \\
(0.898)\end{array}$ & -2608.95 \\
\hline Local heat pump \# ACDD & $\begin{array}{c}14.440 \\
(15.164)\end{array}$ & 53.36 & $\begin{array}{c}-2.839 \\
(14.129)\end{array}$ & -10.49 \\
\hline Central heatpump \# AHDD & $\begin{array}{c}0.072 \\
(2.628)\end{array}$ & 10.67 & $\begin{array}{c}0.753 \\
(1.648)\end{array}$ & 111.63 \\
\hline Central heatpump \# ACDD & $\begin{array}{c}173.687 * * * \\
(22.301)\end{array}$ & 641.77 & $\begin{array}{c}185.113 * * * \\
(22.397)\end{array}$ & 683.99 \\
\hline Number of window AC \#ACDD & $\begin{array}{c}55.386^{* * *} \\
(11.168)\end{array}$ & 204.65 & $\begin{array}{c}49.773 * * * \\
(11.137)\end{array}$ & 183.91 \\
\hline Energy related renovations \#AHDD & $\begin{array}{c}0.161 \\
(0.435)\end{array}$ & 23.87 & $\begin{array}{c}0.012 \\
(0.259)\end{array}$ & 1.78 \\
\hline Energy related renovations \#ACDD & $\begin{array}{l}-4.859 \\
(4.366)\end{array}$ & -17.95 & $\begin{array}{c}-7.791^{*} \\
(4.172)\end{array}$ & -28.79 \\
\hline Thermostat setback \#AHDD & $\begin{array}{c}-4.587 * * * \\
(1.552)\end{array}$ & -680.00 & $\begin{array}{c}-3.508 * * * \\
(0.903)\end{array}$ & -520.04 \\
\hline Year Built (1961-1974) \#AHDD & $\begin{array}{c}-6.644 * * \\
(2.696)\end{array}$ & -984.93 & $\begin{array}{c}-8.860^{* * *} \\
(1.528)\end{array}$ & -1313.44 \\
\hline Year Built (1975-1989) \#AHDD & $\begin{array}{c}-13.452 * * * \\
(2.436)\end{array}$ & -1994.18 & $\begin{array}{c}-14.948^{* * *} \\
(1.387)\end{array}$ & -2215.95 \\
\hline Year Built (1990-1999) \#AHDD & $\begin{array}{c}-11.000 * * * \\
(2.614)\end{array}$ & -1630.68 & $\begin{array}{c}-11.827^{* * *} \\
(1.490)\end{array}$ & -1753.28 \\
\hline Year Built (2000-2009) \#AHDD & $\begin{array}{c}-14.047 * * * \\
(2.564)\end{array}$ & -2082.38 & $\begin{array}{c}-14.991 * * * \\
(1.492)\end{array}$ & -2222.33 \\
\hline Year Built (2010-2015) \#AHDD & $\begin{array}{c}-21.950 * * * \\
(2.976)\end{array}$ & -3253.96 & $\begin{array}{c}-22.759^{* * *} \\
(1.808)\end{array}$ & -3373.89 \\
\hline Year Built (2015-2018) \#AHDD & $\begin{array}{c}-31.677^{* * *} \\
(4.340)\end{array}$ & -4695.93 & $\begin{array}{c}-31.778^{* * *} \\
(2.891)\end{array}$ & -4710.90 \\
\hline Billing period $\mathrm{FE}$ & YES & & YES & \\
\hline Household FE & & & YES & \\
\hline House size control & YES & & & \\
\hline Occupancy control & YES & & YES & \\
\hline Observations & 38,568 & & 38,568 & \\
\hline R-squared & 0.62 & & 0.83 & \\
\hline Number of Households & 3,214 & & 3,214 & \\
\hline Mundlak test: & & stic & $\begin{array}{l}\text { Prob. } \\
\text { 0.00 }\end{array}$ & \\
\hline Hausman test: & & stic & $\begin{array}{l}\text { Prob. } \\
0.00\end{array}$ & \\
\hline
\end{tabular}

Notes: The dependent variable in columns (1) and (3) is monthly electricity usage in kWh. Columns (2) and (4) show the implied annual consumption. The four primary heating system options from the survey are electric baseboard, local heat pump and central heat pumps and the omitted category is electric baseboard. The omitted category for Year Built is houses built before 1961. Dummy variables for the number of occupants are interacted with heating and cooling degree days in both models but are not reported for space purposes. Full regression results are available by request from the authors. Standard errors are clustered by household and billing period are in parentheses, ${ }^{* * *} \mathrm{p}<0.01$, ${ }^{* *} \mathrm{p}<0.05,{ }^{*} \mathrm{p}<0.1$. 
equation (3), a random-effects model, and column (3) displays estimates from the estimation of equation (4), a fixed effects model. Both models also control for billing period as well as occupancy interactions with cooling and heating degree days, where the latter are coded as dummy variables interactions for each occupancy value. In the random effects model we also incorporate a house size control, which is implicitly accounted for in the fixed effects model and has a significant effect on consumption when included in the random effects model. Standard errors are two-way clustered by household and billing period.

The annual electricity consumption implied by these estimated coefficients is presented in Columns (2) and (4). Since the coefficients are in units of average daily heating and cooling degree days per billing month, we obtain annual consumption by multiplying the coefficient estimates from columns (1) and (3) by 147.6 and 3.7 respectively, which are annual $A H D D_{z t}$ and $A C D D_{z t}$ (i.e. $\sum_{t=1}^{12} A H D D_{t}, \sum_{t=1}^{12} A C D D_{t}$ ) averaged across all climate regions ${ }^{13}$

We interact all variables of interest with both $A H D D_{z t}$ and $A C D D_{z t}$ in our main analysis, as presented in equations (3) and (4). However, as New Brunswick is a relatively cold province, we only report variables that are both policy relevant and make sense from the physical point of view. For example, we do not report the coefficient on pool pumps interacted with heating degree days as pool pumps are not used in the heating season, and the coefficient is insignificant. Moreover, most variables interacted with $A C D D_{z t}$ are insignificant and these are not reported in the main results in Table 2 . Table 2 therefore shows a subset of the coefficients from our complete specification. Other included variables that are not reported in the Table are electric water heater, well pump and number of low flow shower heads interacted with heating and cooling degree days, as their coefficients were statistically insignificant.14

\subsection{Model choice: random or fixed effects?}

To evaluate whether the random effects model results in biased coefficient estimates we implement the Hausman [41] and Mundlak [44] tests. Each of these tests seek to determine whether the time-invariant unobservable error component $c_{i}$ is uncorrelated with $u_{i t}$ and the right-hand side regressors in equation (4). If the null hypothesis of uncorrelatedness is rejected, this suggests the random effects model will lead to biased coefficients and the fixed effects model is preferred. Otherwise, the random effects assumptions are satisfied.

\footnotetext{
${ }^{13}$ More specifically, average annualized daily AHDD and ACDD are obtained by summing $A H D D_{z t}$ and $A C D D_{z t}$ across billing months for each customer (where $A H D D_{t}$ and $A C D D_{t}$ for a given $t$ are the same for each customer in climate zone $z$ ), to obtain total AHDD and total ACDD per customer, then calculating the average total AHDD and average total ACDD across customers. For comparison purposes, the annual mean daily AHDD for 2016 and 2019 (the two years before and after our sample period) are 152 and 166, respectively. The annual mean daily ACDD for 2016 and 2019 are 4.3 and 3.2, respectively. Hence, the weather variables used in the analysis are typical in our province of interest.

${ }^{14}$ The full results Table is available from the authors upon request.
} 
The advantage of the Mundlak test relative to the Hausman test is that it permits the use of robust standard errors when the regression errors are heteroskedastic.

The results from these two tests will guide our preference between the random effects or fixed effects model coefficients. The bottom two rows of Table 2 report the chi-squared $\left(\chi^{2}\right)$ statistics for each of the Mundlak and Hausman tests. As shown, the p-value of each test is less than 0.00 , which therefore strongly rejects the null hypothesis of no bias affecting our independent variables of interest. This implies that the fixed-effects specification from column (3) is preferred since it controls for time-constant unobservable variable bias.

Despite the findings of biased inference from the random effects model, in general the results from Table 2 indicate relatively small variations in coefficient values between the random and fixed effects models. For most coefficients, there is less than a 15 percent difference between the estimates for individual variables. Two exceptions are the energy consumption effects of a pool pump and energy-related renovations.

A plausible potential reason for the larger differences between the random and fixed effects models for these variables is the impact of income level, which is unobserved in this sample. For example, higher income households may undertake energy-related renovations at different rates, utilize pool pumps with different intensities and own larger pools that require larger pumps, relative to lower income households. To the extent that income level is constant over the one-year period in our sample, the fixed effects model will net out the effect of income, as well as the mean effect of all other time-constant variables, such as thermal comfort preferences).

\subsection{Coefficient estimates}

Results from column (3) in Table 2 show that owning an additional unit of a dehumidifier raises electricity consumption by $6.1 \mathrm{kWh}$ per month in response to 1 unit increase in average daily HDD (AHDD). Column (4) indicates this translates to an annual increase of $908 \mathrm{kWh} / \mathrm{yr}$ in the colder months. These values are within the range of estimates shown in Table 3, where we compare the findings of the same effects reported in other studies. We focus these comparisons on studies conducted in cool or cold climates in North America and Europe, as these are most relevant to the sample in our analysis. ${ }^{15}$ Houses with pool pumps use substantially more electricity, as expected; the estimated coefficient indicates $1,035 \mathrm{kWh}$ of additional annual electricity use than a house without a pool.

About 32 percent of survey respondents use local heat pumps as a primary source of heating, which is more energy efficient in both colder and hotter months. The other

\footnotetext{
${ }^{15}$ Nevertheless, local climate variations, potential differences in appliance use practices among sample households, and other methodological differences in data collection and analysis, can also lead to variations in effect estimates.
} 
heating sources included in Table 2 are electric baseboards (used by 54 percent of households), and central heat pumps (used by 13 percent of households). ${ }^{16}$ Table 2 shows that houses heating primarily with local heat pumps consume about 2,600 $\mathrm{kWh}$ less electricity annually than houses with electric baseboards, and all of this excess electric baseboard consumption occurs during the heating season. Local heat pumps do not consume statistically different quantities of electricity compared to baseboards during the cooling season. On the other hand, statistically central heat pumps use the same amount of electricity as electric baseboards during the heating season, but $684 \mathrm{kWh}$ more electricity during the cooling season. Taken together, these heat pump estimates suggest local heat pumps are not often used for cooling in summer (although they are capable), whereas central heat pumps are.

An additional window air conditioner has a statistically significant effect on monthly electricity consumption in the cooling season, resulting in an increase of about $184 \mathrm{kWh}$ per year. Investing in an extra energy related renovation has a borderline significant effect on reducing cooling demand but does not have a statistically significant effect on heating demand. The associated savings from these behaviours are modest and total about 29 kWh per year.

The effect of house age in Table 2 is measured in the construction year ranges as reported in the survey: Before 1961, 1961-1974, 1975-1989, 1990-1999, 2010-2015 and 2015-2018. In Table 2 homes built before 1961 are the omitted category so the home age coefficients are interpreted relative to the oldest homes. With the exception of 1990-1999, homes of progressively newer vintages tend to consume less electricity, and this effect is largest for the two most recent age categories. On average, the two newest vintages save about $340 \mathrm{kWh}$ per year relative to their preceding age category. ${ }^{17}$

We formally assessed if the differences in the coefficients from vintage to vintage are statistically significant by testing individual hypotheses evaluating whether each coefficient is statistically different from the preceding vintage (using Wald tests). All of our tests strongly reject their null hypotheses. The highest p-value is $1.8 \%$ for the test between coefficients on the vintage years of 1990-1999 and 2000-2009. Most of the other p-values are lower than $0.02 \%$.

These results suggest that since the 1990s there has been a clear and statistically significant trend towards reductions in energy consumption that can be attributed to progressively newer homes. This could be a result of greater emphasis being placed on house energy performance over time among home builders, and possibly reinforced by the adoption of building energy codes from 2012 onwards.

\footnotetext{
${ }^{16}$ As previously noted, electric baseboard heating is the omitted heating system category in Table 2 so that the coefficients on local and central heat pumps are interpreted as their consumption effect relative to electric baseboards.

${ }^{17}$ This value results from the calculation $[(4710.9-3373.89) / 3+(3373.89-2222.33) / 5] / 2$, using the annual savings values from the two newest year built categories from the fixed effects model in Table 2.
} 


\subsection{Energy conservation measures discussion}

\subsubsection{Heat pumps}

An important question for this study and for policy guidance is: do heat pumps in practice use substantially less electricity than electric baseboards? The annual consumption levels of heat pumps and electric baseboard heaters have been estimated in prior studies, as shown in Table 3. The simple average of annual electric baseboard estimates across these studies is $10,585 \mathrm{kWh}$. Two studies from Quebec measured heat pump annual consumption levels, although these did not distinguish between centrally-ducted and local heat pump systems, and found average annual consumption values of 11,805 kWh. Our study disaggregates between local and central heat pumps and finds that central heat pumps (but not local heat pumps) consume more electricity than electric baseboards, and this higher consumption is driven by cooling season usage.

Table 3: Estimated end use effects of appliances from prior studies and published guidance (kWh/yr)

\begin{tabular}{|c|c|c|c|c|c|c|c|c|}
\hline & $\begin{array}{c}\text { Newsham and } \\
\text { Donnelly (2013) }\end{array}$ & $\begin{array}{c}\text { Manitoba Hydro } \\
\text { (2011) }\end{array}$ & $\begin{array}{c}\text { Bernard and } \\
\text { Lacroix (2005) }\end{array}$ & $\begin{array}{l}\text { Tiedemann } \\
\text { (2007) }\end{array}$ & $\begin{array}{l}\text { Lafrance and } \\
\text { Perron (1994) }\end{array}$ & $\begin{array}{c}\text { Sebold and } \\
\text { Parris (1989) }\end{array}$ & $\begin{array}{c}\text { Burlington } \\
\text { Hydro (2020) }\end{array}$ & $\operatorname{EREN}(2020)$ \\
\hline & Canada & Manitoba & Quebec & $\begin{array}{c}\text { British } \\
\text { Columbia }\end{array}$ & Quebec & $\begin{array}{c}\text { N. Midwest, } \\
\text { USA }\end{array}$ & S. Ontario & USA \\
\hline Dehumidifier & & & & & & & $504-3,024$ & 700 \\
\hline Pool Pump & & 4,898 & 2,114 & 3,912 & 1,800 & & 1,944 & \\
\hline Electric Baseboard Heating & 8,600 & $10,518-16,556^{*}$ & 12,926 & $5,037^{*}$ & 9,873 & & & \\
\hline Window AC units & 396 & 675 & & 207 & & 500 & & \\
\hline Heat Pumps Heating & & & 13,643 & & 9,966 & & & \\
\hline
\end{tabular}

Notes: * above denotes it is not clear whether this is baseboard heating only or includes other delivery mechanisms.

For houses that heat primarily with central heat pumps, our estimated fixed effects model coefficient finds that these systems consume the same amount of electricity compared to electric baseboards during the heating season, and more than electric baseboards during the cooling season 18 More precisely, the annual consumption results from Table 2 column (4) indicate central heat pumps consume about $684 \mathrm{kWh}$ more annually than electric baseboards. On the other hand, local heat pumps consume 2,609 fewer kWh annually compared to electric baseboards, and 3,293 fewer kWh than central heat pumps.

Heat pumps are relatively expensive components of a space conditioning system, and many utilities have incentives to encourage their adoption in both new construction and in retrofits. This is because they are, in principle, much more efficient than other heating

\footnotetext{
${ }^{18}$ As noted in section 3.2 the heating season here is measured as periods when the outdoor temperature falls below 18 degrees celsius, and the cooling season when the temperature is above 18 degrees celsius.
} 
systems. In our study, the traditional incumbent heating system was electric baseboards, which have a coefficient of performance (COP) of 1 , that is, for every one unit (in $\mathrm{kWh}$ ) of electricity of input, one unit of heat is output. Air-to-air heat pumps, the most common alternative to electric baseboards in a residential context, are typically considered, in a simplified analysis, to have a COP of approximately 3: for every one unit of electricity input, three units of heat energy are extracted from the outdoor air and brought indoors. In the context of heat pumps replacing baseboards, simple engineering estimates often assume that the heat pumps will assume all of the heat load previously met by baseboards, and therefore suggest that heat pumps will lower heating energy use by $2 / 3$, or 67 percent. For a typical electrically-heated house in a cool climate, this might equate to a saving of 30-35 percent of total annual electricity use. Our results show that houses with local (or ductless) heat pumps as their primary heating system do use substantially less electricity than those with electric baseboards as the primary system, all else being equal. However, the conservation effect is much smaller than the simple engineering estimate: 14 percent of total energy relative to electric baseboards ${ }^{19}$

Other studies of the field performance of heat pumps in heating-dominated climates have found similar results. In Ontario, [53] evaluated a heat pump incentive pilot involving 100 homes that had formerly used electric baseboards as their sole heating system. Estimated energy use, based on 12 months of measured consumption, declined by only 11.2 percent compared to total pre-pilot energy use. Similarly, and also in Ontario, [54] evaluated a heat pump incentive pilot involving 100 homes that had formerly used electric baseboards or electric furnaces as their sole heating system. Estimated energy savings, based on 12 months of measured consumption, were only 7.9 percent compared to total pre-pilot energy use. [55] conducted a multiple regression-based analysis using billing data of the effectiveness of heat pump retrofits in Nova Scotia. Focusing on the subset where minisplit heat pumps were installed in 118 exclusively electrically-heated houses, annual savings of $3,504 \mathrm{kWh}$ were reported. They concluded that this saving was well below estimates from standard methods pre-installation. [46] report on a large study in the northwest USA where ductless minisplit heat pumps replaced electric heating. For houses with no self-reported supplemental fuel use, a billing data analysis indicated average annual energy savings were $2,718 \mathrm{kWh}(\mathrm{N}=2,295)$, or about 15 percent of pre-installation total energy use, very similar to the results in our study. However, a CDA on these data suggested about a third of savings were given back for increased space temperature and occupancy. Finally, 56, using a CDA method to analyze data from $\geq 1000$ households in Norway, found that the energy saving potential of heat pumps was offset by other changes in energy consumption behaviour.

There are several reasons in the previously cited literature for lower performance than simple engineering estimates:

\footnotetext{
${ }^{19}$ Based on the calculation $2,609 / 18,847$, where the denominator is annual average in-sample electricity use.
} 
- COP declines as outdoor temperature goes down, especially for older heat pumps that might not have been specifically designed for cold climates [57]. Therefore, the actual average operating COP may be substantially lower than the value of 3 often assumed.

- Some electric baseboards are retained as supplementary heat sources and are used even after the heat pump is installed. In some cases, this permits a greater fraction of the house volume to be heated, thus increasing comfort and space utilization. 20

- People exchange savings for increased comfort. This is a classic rebound effect: when the heating bill is lower some people increase their thermostat setpoint.

Another potential energy penalty is that people who did not have air conditioning prior to obtaining a heat pump will then use the heat pump in cooling mode in the summer, thus adding to total electricity use. Again, this brings a tangible comfort benefit to the occupants, and is thus seen as a good thing by heat pump owners, even with an energy penalty. Our analysis shows that a central heat pump is associated with an airconditioning load of $684 \mathrm{kWh} / \mathrm{yr}$, higher than the estimated use of a standard window air conditioner in our sample, of about $184 \mathrm{kWh} / \mathrm{yr}$.

Our results that central, ducted heat pumps use significantly more energy than local heat pumps may arise because they are used to service the entire house volume all of the time, whereas local heat pumps might be used in specific zones at least some of the time. Overall, local heat pumps generally realize substantial energy savings and improve comfort. However, measured savings are substantially lower than typically forecast, which may impact the cost-benefit equation for homeowners. It also has implications for program design on the part of policy-makers. From a policy perspective, our finding that central heat pumps do not save electricity compared to electric baseboards may call into question whether program dollars are best spent incentivizing their adoption.

\subsubsection{Thermostat setback}

Houses in which the householder indicated employing thermostat setbacks used statisticallysignificantly less electricity during the heating season, as expected; the estimated annual saving is $520 \mathrm{kWh} / \mathrm{yr}$. [38] also used CDA to estimate this effect at $390 \mathrm{kWh} / \mathrm{yr}$ per degree of setback, for electric heating systems, and this is broadly consistent with the effect reported in the current analysis. In an experimental study in full-scale test houses with natural gas heating, [58] found winter heating savings of about 2.2-2.5 percent per degree of setback, when setbacks were implemented for approximately seven hours per day. Assuming a $2{ }^{\circ} \mathrm{C}$ setback that persists for similar periods, a 2.35 percent energy saving per degree of setback, the middle of the savings range in their study, results in savings

\footnotetext{
${ }^{20}$ In our estimated model this scenario would inflate the estimated consumption for heat pumps as households were asked about their primary heating system.
} 
of approximately $780 \mathrm{kWh} / \mathrm{yr}{ }^{21}$ This is somewhat higher than our estimate, however the study setting was Ottawa, Canada, a region with colder winters than our jurisdiction under study, which may account for the higher savings. A basic engineering calculation results in savings within a very similar range as our estimate. Heat loss (and thus the energy to maintain the desired indoor temperature) is proportional to the temperature difference between inside and outside; in a cold climate this temperature difference may be estimated at approximately $20{ }^{\circ} \mathrm{C}$. A setback of $2{ }^{\circ} \mathrm{C}$ that persists for half of the time, suggests a saving of 5 percent $(2 / 20 * 0.5)$, which, on a total heating use of $11,200 \mathrm{kWh} / \mathrm{yr}$ (the average of the electric baseboard and heat pump annual consumption estimates in Table 3) yields a saving of $560 \mathrm{kWh} / \mathrm{yr}$.

Overall, a synthesis of research results, including this current study, indicate that thermostat setbacks do yield annual heating energy savings of approximately 500-800 $\mathrm{kWh} / \mathrm{yr}$, and may often be realized by utilizing equipment the homeowners already has. As such, continued policy support for this energy saving strategy is justified.

\subsubsection{Renovations}

Houses reporting having recently completed energy-efficiency retrofits used less electricity during the cooling season; the estimated coefficient was a saving of about $29 \mathrm{kWh} / \mathrm{yr}$ per renovation. However, the coefficient is borderline significant at the 10 percent significance level. This may be due in part to the high heterogeneity in the savings associated with the different categories of energy renovations. For example, insulation retrofits typically save significantly more energy than sealing air leaks [59, 60]. Due to the way this variable was assessed and developed in the analysis, it is difficult to compare to data collected elsewhere. Energy related renovations completed represents the response to a series of survey questions, "Please indicate if you have recently completed the following: insulate your basement, add insulation to your attic, add insulation to your walls, replace exterior doors or windows, install LED lights, install weather-stripping, caulking, etc." Each of these measures is unlikely to have an equal effect. Further "recently" in the survey was not defined and may have been interpreted differently by different respondents. We also do not know the state of the house prior to the renovation, nor the extent of the renovation; e.g., if a respondent reported adding insulation to their attic we do not know how much insulation was there before the renovation nor how much insulation was added. Given the importance of renovations in future code development, better data on previous renovations and their effects should be a priority.

These measures have different costs and implementation challenges, and, given that we cannot parse out the effects of each measure, a cost-benefit analysis for policy purposes is not possible. Nevertheless, the fact that we estimated a modest savings effect is encouraging and supportive of further research on these measures.

\footnotetext{
${ }^{21}$ These savings were converted to $\mathrm{kWh}$ from MJ of natural gas.
} 


\section{Conclusion}

We conducted a conditional demand analysis on electricity use data from approximately 3,200 electrically-heated dwellings in a cold climate in North America that exhibits high electrification of end-usage. The results provide estimates of the effectiveness of various energy efficiency measures on electricity usage post-installation, at a time when the international community looks towards increasing the electrification and decarbonization of energy end-uses in order to reach climate policy targets.

Evaluating efficiency investments on the basis of realized energy use is important because such analyses estimate their effects including secondary interactions among appliances and energy-using equipment, as well as behavioural responses such as the rebound effect. In the end, it is not theoretical savings that matter, but rather the net savings on actual energy consumption using robust statistical models with low coefficient bias. This information can guide policy-makers in deciding which energy efficiency measures are deserving of the most support, and what appropriate incentive levels might be with respect to the cost of a specific measure and its expected, i.e. realized, energy reduction effect.

A further contribution of our work is to evaluate the evidence for coefficient bias in the random effects models that are frequently used in conditional demand analyses. While on the basis of statistical tests we find that the random effect estimator is rejected in favour of the fixed effects estimator, most of the individual coefficient estimates exhibit only small variations between models, with a few exceptions. Overall, the estimates of energy use by specific appliances and conservation measures were quite robust across different statistical estimators, and reasonable when compared to relevant prior studies using various estimation methods.

Finally, this analysis reinforces the value of CDA as a technique to derive policyguiding estimates. As relevant energy use data become potentially more available (e.g. smart meter data, smart thermostat data), and survey data become easier to collect via on-line methods, CDA may become a more attractive research tool for climate policy guidance going forward. 


\section{Acknowledgements}

The authors gratefully acknowledge NB Power for generously providing the anonymized survey data on which the analysis was based, and National Research Council (NRC) colleagues Ghassan Marjaba and Heather Knudsen for support via NRC-Construction's Net Zero Energy Research project. 


\section{References}

[1] Daniel Steinberg, Dave Bielen, Josh Eichman, Kelly Eurek, Jeff Logan, Trieu Mai, Colin McMillan, Andrew Parker, Laura Vimmerstedt, and Eric Wilson. Electrification \& decarbonization: Exploring u.s. energy use and greenhouse gas emissions in scenarios with widespread electrification and power sector decarbonization, 2017. National Renewable Energy Laboratory, U.S. Department of Energy.

[2] Joeri Rogelj, Drew Shindell, Kejun Jiang, Solomone Fifita, Piers Forster, Veronika Ginzburg, Collins Handa, Haroon Kheshgi, Shigeki Kobayashi, Elmar Kriegler, Luis Mundaca, Roland Seferian, and Maria Virginia Vilarino. Mitigation Pathways Compatible with $1.5^{\circ} \mathrm{C}$ in the Context of Sustainable Development. In Global Warming of $1.5^{\circ} \mathrm{C}$. An IPCC Special Report on the impacts of global warming of $1.5^{\circ} \mathrm{C}$ above pre-industrial levels and related global greenhouse gas emission pathways, in the context of strengthening the global response to the threat of climate change, sustainable development, and efforts to eradicate poverty, chapter 2, pages 93-174. IPCC, 2018.

[3] UN Environment. Towards a zero-emission, efficient, and resilient buildings and construction sector, 2017. UN Environment and International Energy Agency.

[4] Elham Delzendeh, Song Wu, Angela Lee, and Ying Zhou. The impact of occupants' behaviours on building energy analysis: A research review. Renewable and Sustainable Energy Reviews, 80:1061-1071, 2017.

[5] IEA. Energy technology perspectives 2017: Catalyzing energy technology transformations, 2017. International Energy Agency, Paris, France.

[6] Carlos Calderon, Chris Underwood, Jialing Yi, Adrian Mcloughlin, and Brian Williams. An area-based modelling approach for planning heating electrification. Energy Policy, 131:262-280, 2019.

[7] IPCC. Summary for Policymakers. In V. Masson-Delmotte, P. Zhai, H. Pőrtner, D. Roberts, P.R. Shukla J. Skea, A. Pirani, W. Moufouma-Okia, R. Pidcock C. Péan, S. Connors, J.B.R. Matthews, Y. Chen, X. Zhou, M.I. Gomis, E. Lonnoy, T. Maycock, M. Tignor, and T. Waterfield, editors, Global Warming of $1.5^{\circ}$ C. An IPCC Special Report on the impacts of global warming of $1.5^{\circ} \mathrm{C}$ above pre-industrial levels and related global greenhouse gas emission pathways, in the context of strengthening the global response to the threat of climate change, sustainable development, and efforts to eradicate poverty. 2018.

[8] Michael Parti and Cynthia Parti. The total and appliance-specific conditional demand for electricity in the household sector. The Bell Journal of Economics, 11:309$321,1980$. 
[9] Robert Bartels and Denzil G. Fiebig. Integrating direct metering and conditional demand analysis for estimating end-use loads. The Energy Journal, 11(4):79-97, 1990.

[10] Cheng Hsiao, Dean C. Mountain, and Kathleen Ho Illman. A bayesian integration of end-use metering and conditional-demand analysis. Journal of Business 6 Economic Statistics, 13(3):315-326, 1995.

[11] Merih Aydinalp-Koksal and V Ismet Ugursal. Comparison of neural network, conditional demand analysis, and engineering approaches for modeling end-use energy consumption in the residential sector. Applied Energy, 85(4):271-296, 2008.

[12] Lukas G. Swan and V. Ismet Ugursal. Modeling of end-use energy consumption in the residential sector: A review of modeling techniques. Renewable and Sustainable Energy Reviews, 13:1819-1835, 2009.

[13] Alfonso Aranda, Germán Ferreira, M.D. Mainar-Toledo, Sabina Scarpellini, and Eva Llera Sastresa. Multiple regression models to predict the annual energy consumption in the spanish banking sector. Energy and Buildings, 49:380-387, 2012.

[14] Nelson Fumo. A review on the basics of building energy estimation. Renewable and Sustainable Energy Reviews, 31:53-60, 2014.

[15] Aurélie Foucquier, Sylvain Robert, Frédéric Suard, Louis Stéphan, and Arnaud Jay. State of the art in building modelling and energy performances prediction: A review. Renewable and Sustainable Energy Reviews, 23:272-288, 2013.

[16] Douglas W. Caves, Joseph A. Herriges, Kenneth E. Train, and Robert J. Windle. A bayesian approach to combining conditional demand and engineering models of electricity usage. The Review of Economics and Statistics, 69(3):438-448, 1987.

[17] Bodil Merethe Larsen and Runa Nesbakken. Household electricity end-use consumption: results from econometric and engineering models. Energy Economics, 26(2):179-200, 2004.

[18] Katrina Jessoe, Maya Papineau, and David Rapson. Utilities included: Split incentives in commercial electricity contracts. The Energy Journal, 41(5), 2020.

[19] Canada Energy Regulator. Canada's renewable power landscape 2017 - energy market analysis, 2017.

[20] Natural Resources Canada. Comprehensive energy use database, natural resources canada, 2019. 
[21] N.P Isaacs, M Camilleri, L Burrough, A Pollard, K Saville-Smith, R Fraser, $\mathrm{P}$ Rossouw, and J Jowett. Energy use in new zealand households: Final report on the household energy end-use project (heep). BRANZ Study, Report 221, 2010.

[22] Anibal De Almeida, Paula Fonseca, Barbara Schlomann, and Nicolai Feilberg. Characterization of the household electricity consumption in the eu, potential energy savings and specific policy recommendations. Energy and Buildings, 43(8):1884-1894, 2011.

[23] Danny S Parker. Research highlights from a large scale residential monitoring study in a hot climate. Energy and Buildings, 35(9):863-876, 2003.

[24] D.J Nelson, A.J Berrisford, and J Xu. Mels: What have we found through end-use metering? Proceedings of ACEEE Summer Study on Energy Efficiency in Buildings (Pacific Grove, USA), 9:274-285, 2014.

[25] NRCan. The energuide label are established. Technical report, 2019.

[26] Dennis J. Aigner, Cynts Sorooshian, and Pamela Kerwin. Conditional Demand Analysis for Estimating Residential End-Use Load Profiles. The Energy Journal, 0(Number 3):81-98, 1984.

[27] AG Lawrence and M Parti. Survey of conditional energy demand models for estimating residential unit energy consumption coefficients, 1984. Angel Economic Reports, Cupertino, CA (USA); Applied Econometrics, Inc.

[28] R.G. Archibald, D.H. Finifter, and C.E. Moody. Seasonal variation in residential electricity demand: Evidence form survey data. Applied Economics, 14:167-181, 1982.

[29] Florida Power \& Light. A model of residential energy consumption and appliance ownership, 1986. Florida Power \& Light Company.

[30] Sanford V. Berg. Survey of household end-use consumption, 1988. Public Utility Research Center Working Paper.

[31] K H Tiedemann. Using conditional demand analysis to estimate residential energy use and energy savings, 2007. European Council for an Energy Efficient Economy Summer Study.

[32] Eduardo Krüger and Givoni Baruch. Predicting thermal performance in occupied dwellings. Energy and Buildings, 36:301-307, 2004.

[33] Gaétan Lafrance and Dominique Perron. Evolution of residential electricity demand by end-use in quebec 1979-1989: a conditional demand analysis. Energy Studies Review, 6(2):164-173, 1994. 
[34] Denzil G. Fiebig, Robert Bartels, and Dennis J. Aigner. A random coefficient approach to the estimation of residential end-use load profiles. Journal of Econometrics, 50:297-327, 1991.

[35] George Judge, W.E. Griffiths, R.C. Hill, H. Lutkepohl, and T.C. Lee. The theory and practice of econometrics, 2nd ed. New York, NY: Wiley, 1985.

[36] FD Sebold and KM Parris. Residential end-use energy consumption: a survey of conditional demand estimates, 1989. Electric Power Research Institute, Palo Alto, CA.

[37] Stephanie J Battles. Validation of conditional demand estimates: does it lead to model improvements? Proceedings of the ACEEE Summer Study on Energy Efficiency in Buildings (Pacific Grove, CA, USA), 7:13-22, 1994.

[38] Guy R Newsham and Cara L Donnelly. A model of residential energy end-use in canada: Using conditional demand analysis to suggest policy options for community energy planners. Energy policy, 59:133-142, 2013.

[39] L Bauwens, D Fiebig, and M Steel. Estimating end-use demand: a bayesian approach. Journal of Business and Economic Statistics, 12(2):221-231, 1994.

[40] Robert Bartels and Denzil G. Fiebig. Residential end-use electricity demand: Results from a designed experiment. The Energy Journal, 21:51-81, 2000.

[41] Jerry A Hausman. Specification tests in econometrics. Econometrica: Journal of the econometric society, pages 1251-1271, 1978.

[42] B Baltagi. Econometric analysis of panel data, 4th edition. New York, NY: Wiley \& Sons, 2008.

[43] Dora L Costa and Matthew E Kahn. Do liberal home owners consume less electricity? A test of the voluntary restraint hypothesis. Economic Letters, 119(2):2010-2012, 2013.

[44] Y. Mundlak. On the pooling of time series and cross section data. Econometrica, 46(1):69-85, 1978.

[45] Maya Papineau. Big data meets local climate policy: Energy star time-of-day savings in washington, dc's municipal buildings. IAEE Energy Forum Montreal Special Issue, pages $13-14,2019$.

[46] D. Baylon, P. Storm, and D. Robison. Ductless heat pump impact \& process evaluation: Billing analysis report, 2013. Ecotope Inc., for the Northwest Energy Efficiency Alliance, NEEA Report No. 13-262. 
[47] ASHRAE. ASHRAE handbook fundamentals, 2009. American Society of Heating, Refrigeration and Air-Conditioning Engineers.

[48] X. Zhang, G. Flato, M. Kirchmeier-Young, L. Vincent, H. Wan, X. Wang, R. Rong, J. Fyfe, G. Li, and V.V. Kharin. Changes in Temperature and Precipitation Across Canada. In E. Bush and D.S. Lemmen, editors, Canada's Changing Climate Report. 2019.

[49] Environment Canada. Historical data, 2020. Available at https://climate. weather.gc.ca/historical_data/search_historic_data_e.html.

[50] J. M. Wooldridge. Econometric Analysis of Cross Section and Panel Data, Second Edition. Cambridge, MA: The MIT Press, 2010.

[51] Muhammad Azam. Does environmental degradation shackle economic growth? A panel data investigation on 11 asian countries. Renewable and Sustainable Energy Reviews, 65:175-182, 2016.

[52] Matthew J Kotchen. Longer-run evidence on whether building energy codes reduce residential energy consumption. Journal of the Association of Environmental and Resource Economists, 2017.

[53] A Marshall, A Roma, C Kan, and Colby J. Enwin Utilities ltd. residential ductless heat pump pilot evaluation, 2015. Report for the Independent Electricity System Operator.

[54] A Marshall, J Christensen, A Chamberlain, C Kan, and Colby J. Hydro One Networks, Inc. air-source heat pump advantage pilot evaluation, 2017. Report for the Independent Electricity System Operator.

[55] M-C Hamelin, N. Michaud, and E. Chartrand. Establishing the energy performance of mini-split and central air-source heat pumps through billing analysis, 2018. International Energy Policy \& Programme Evaluation Conference (Vienna, Austria).

[56] Bente Halvorsen and Bodil Merethe Larsen. How do investments in heat pumps affect household energy consumption? Technical report, Discussion Papers, 2013.

[57] D. Korn, J. Walczyk, A. Jackson, A. Machado, J. Kongoletos, and E. Pfann. Ductless mini-split heat pump impact evaluation, 2016. Cadmus Group Inc., for The Electric and Gas Program Administrators of Massachusetts and Rhode Island.

[58] M. M. Manning, M.C. Swinton, F. Szadkowski, J. Gusdorf, and K. Ruest. The effects of thermostat setting on seasonal energy consumption at the ccht twin house facility. ASHRAE Transactions, 113:1-12, 2007. 
[59] Lauren Giandomenico, Maya Papineau, and Nicholas Rivers. A systematic review of energy efficiency home retrofit evaluation studies, 2020. Working Paper.

[60] Jing Liang, Yueming Qiu, Timothy James, Benjamin L. Ruddell, Michael Dalrymple, Stevan Earl, and Alex Castelazo. Do energy retrofits work? Evidence from commercial and residential buildings in Phoenix. Journal of Environmental Economics and Management, 92:726-743, 2018. 


\section{Appendix}

\section{A. Data cleaning and variable coding}

\section{A1. Consumption data}

Our general approach to data cleaning was to remove, or cap, extreme values for the major variables in the model. In common with prior work in this area, we considered univariate outliers only. For electrical energy use, we dropped cases where total annual energy use was more than 3 standard deviations from the mean, or if usage in any billing period was $>10000 \mathrm{kWh}$, as high outliers. Given that we had a sample of houses in a cold climate using electric heat, we also dropped cases where total annual energy use was $<3000 \mathrm{kWh}$, or if usage in any billing period was $<100 \mathrm{kWh}$, as low outliers. We also excluded a small number of cases that had reported ownership of an electric vehicle or local renewable generation because their monthly grid-sourced electricity consumption would be considerably higher or lower (respectively) than their counterparts.

\section{A2. Survey data}

Some variables that were reported in categories were recoded as numeric, where appropriate. For example, on the survey the variable house area (finished area without garage) was originally reported as $<601$ square feet (s.f.), $601-1200$ s.f., $1201-1800$ s.f., $1801-2400$ s.f., $>2401$ s.f., and these were recoded to $600,900,1500,2100$, and 2700 , respectively; responses of "Don't know" were coded as missing and therefore excluded from the analysis. The survey also collected data on year of home construction in the following year built categories: before 1961, 1961-1974, 1975-1989, 1990-1999, 2000-2009, 2010-2015, and after 2015. Each year built range was recoded to an indicator (or dummy) variable to reflect the seven age range categories.

The survey also asked households about their thermostat usage in winter time. Specifically, households responded whether they turn down their thermostat while sleeping, when no one is home, both or never. We coded the thermostat setback variable as a dummy variable that takes the value of one if the household turns down their thermostat anytime of the day and zero otherwise.

\section{A3. Weather data}

Using postal code data and weather zones in New Brunswick, we identified six major cities/towns that are representative of the different weather zones of the province, allocated each household location to one of these six geographical regions, and obtained daily weather data from Environment Canada for each of the six cities from 2016-2018 to calculate HDD and CDD. Daily HDD and CDD were calculated and then totalled for each billing period and each household in a specific region. Finally, to simplify coefficient interpretation, we divided cumulative HDD and CDD by the number of days in that billing period to arrive at average daily HDD and CDD by billing month (hereafter AHDD and ACDD respectively). Table A1 presents an example of weather data for one of the six regions for the 2017 calendar year. It illustrates that heating days are by far more prevalent than cooling days, which is typical for this coastal province with cold winters and mild summers. 
Table A1: Example CDD and HDD data for one example region for the 2017 calendar year

\begin{tabular}{lccccccccccccc}
\hline Month (2017) & 1 & 2 & 3 & 4 & 5 & 6 & 7 & 8 & 9 & 10 & 11 & 12 & Total \\
\hline CDD18 & 0 & 0 & 0 & 0 & 4 & 30 & 53 & 37 & 31 & 2 & 0 & 0 & 157 \\
HDD18 & 748 & 691 & 690 & 373 & 215 & 69 & 15 & 33 & 59 & 205 & 503 & 800 & 4401
\end{tabular}

